\title{
Performance measurement of insurance firms using a two-stage DEA method
}

\author{
Raha Jalili Sabet $^{* a}$ and Arefeh Fadavi ${ }^{\mathrm{b}}$
}

${ }^{a}$ Master student, Department of management, Islamic Azad University, Central Branch, Tehran, Iran ${ }^{b}$ Assistant Professor, Department of management, Islamic Azad University, Central Branch, Tehran, Iran

\begin{tabular}{|c|c|}
\hline$\overline{A \text { A T I C L E I N F O }}$ & A B S T R A C T \\
\hline $\begin{array}{l}\text { Article history: } \\
\text { Received April } 25,2012 \\
\text { Received in revised format } \\
20 \text { October } 2012 \\
\text { Accepted } 22 \text { October } 2012 \\
\text { Available online } \\
\text { October } 242012 \\
\text { Keywords: } \\
\text { Insurance } \\
\text { Performance measurement }\end{array}$ & $\begin{array}{l}\text { Measuring the relative performance of insurance firms plays an important role in this industry. } \\
\text { In this paper, we present a two-stage data envelopment analysis to measure the performance of } \\
\text { insurance firms, which were active over the period of 2006-2010. The proposed study of this } \\
\text { paper performs DEA method in two stages where the first stage considers five inputs and three } \\
\text { outputs while the second stage considers the outputs of the first stage as the inputs of the second } \\
\text { stage and uses three different outputs for this stage. The results of our survey have indicated } \\
\text { that while there were } 4 \text { efficient insurance firms most other insurances were noticeably } \\
\text { inefficient. This means market was monopolized mostly by a limited number of insurance firms } \\
\text { and competition was not fare enough to let other firms participate in economy, more efficiently. }\end{array}$ \\
\hline
\end{tabular}
DEA

Two-stage DEA

\section{Introduction}

Performance measurement is one of the most important issues among insurance firms and there are many studies focusing on measuring the relative efficiencies of insurance firms in this sector (Barros et al., 2010; Cummins \& Xie, 2008). China, for instance, joined world trade organization in 2001 and had to fully open up its insurance market to foreign rivals by 2006. However, the domestic insurance market was overwhelmingly dominated by limited number of either state-owned or state-controlled companies. As the market was still underdeveloped and the demand for insurance was rising significantly, there was a huge potential, opportunities as well as challenges for non-state, foreign and joint-venture insurance companies. In such circumstances, efficiency was a key concern of policy makers to encourage further development of the insurance industry. Yao et al. (2007) implemented a panel data set of 22 companies over the period 1999-2004 to assess their efficiency scores by using a data envelopment analysis (DEA) technique and decomposed the productivity growth into technical efficiency improvement and technological progress by building a Malmquist Index. They also used

*Corresponding author. Tel: +989123074583

E-mail addresses: jalili.raha@gmail.com (R. Jalili Sabet) 
an econometric technique to determine the key determinants of efficiency. The empirical results recommended the direction of how to improve firm efficiency. They also reported that firm size, ownership structure, mode of business and human capital play essential role in firm performance. Cummins et al. (2010) investigated economies of scope in the US insurance industry over the period 1993-2006. They examined the conglomeration hypothesis, which holds that insurance companies could optimize by diversifying across market, versus the strategic focus hypothesis, which holds that companies optimize by focusing on core markets. They investigated whether it is benefitial for insurers to give both life-health and property-liability insurance or to specialize in one major industry segment. They estimated cost, revenue, and profit efficiency utilizing DEA and examined for scope economies by regressing efficiency scores on control variables and an indicator for strategic focus.

Yang (2006) used a two-stage DEA model to provide valuable managerial insights when evaluating the dual effects of operating and business strategies for the Canadian insurance industry. The proposed model permitted integration of the production performance and investment performance for the insurance firms and provided management overall performance evaluation and how to access efficiency systematically for the insurers involved. The results indicated that the Canadian insurance industry operated efficiently during the investigation period.

\section{Problem Statement}

We first present the problem statement of the proposed DEA method implemented in this paper. In a DEA method, there are normally some inputs and outputs related to all decision-making units. Let $x_{i j}$ be the inputs for one of decision-making unit with $i=1, \ldots, m$ and $y_{r j}$ be the outputs of the same units with $r=1, \ldots, s$ and $j=1, \ldots, n$ and suppose $u_{i}$ and $v_{j}$ are the dual variables associated with $x_{i}$ and $y_{j}$, respectively. The constant return to scale DEA modeling formulation is as follows,

$\max$

$$
Z=\frac{\sum_{r=1}^{s} u_{r} y_{r .}}{\sum_{i=1}^{m} v_{i} x_{i}}
$$

subject to $\frac{\sum_{r=1}^{s} u_{r} y_{r j}}{\sum_{i=1}^{m} v_{i} x_{i j}} \leq 1$.

Model (1) is the basic DEA, which can be solved $j$ times to determine the efficiencies of various units. However, since model (1) is nonlinear in structure, Charles et al. (1978) proposed a simple modification of the objective function to convert model (1) into a simple linear programming problem as follows,

$$
\begin{array}{ll}
\max & Z=\sum_{r=1}^{s} u_{r} y_{r .} . \\
\text { subject to } \quad & \frac{\sum_{r=1}^{s} u_{r} y_{r j}}{\sum_{i=1}^{m} v_{i} x_{i j}} \leq 1 . \\
& \sum_{i=1}^{m} v_{i} x_{i .}=1
\end{array}
$$




$$
u_{r}, v_{i} \geq 0, \quad j=1, \ldots, n
$$

\section{Two-stage DEA}

As we explained, the input oriented DEA is formulated as follows,

$$
\max E=\sum_{r=1}^{s} u_{r} y_{r p}
$$

subject to

$\sum_{r=1}^{s} u_{r} y_{r j}-\sum_{i=1}^{m} v_{i} x_{i j} \leq 0, \quad j=1, \cdots, n$

$\sum_{i=1}^{m} v_{i} x_{i p}=1$,

$v_{i} \geq \varepsilon, \quad i=1, \cdots, n$

$u_{r} \geq \varepsilon . \quad r=1, \cdots, s$

Now an intermediate unit $z_{p j}, p=1, \cdots, q$ according to Fig. 1 can be depicted as follows,

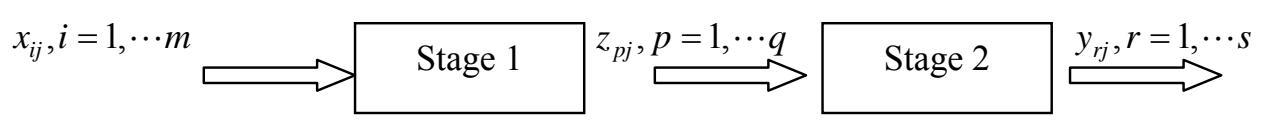

Fig. 1. A two-stage DEA

Let $E_{k}^{1}$ and $E_{k}^{2}$ be the efficiencies of stage 1 and 2, respectively, which yields $E_{k}=E_{k}^{1} \times E_{k}^{2}$ and the new DEA model can be written as follows (Charles et al., 1996; Banker, 1984),

$E_{k}^{1}=\max \sum_{p=1}^{q} w_{p} Z_{p k}$

subject to

$\sum_{i=1}^{m} v_{i} X_{i k}=1$,

$\sum_{r=1}^{s} u_{r} Y_{r k}-E_{s} \sum_{i=1}^{m} v_{i} X_{i k}=0$

$\sum_{r=1}^{s} u_{r} Y_{r j}-\sum_{i=1}^{m} v_{i} X_{i j} \leq 0, \quad j=1, \ldots ., n$,

$\sum_{p=1}^{q} w_{p} Z_{p j}-\sum_{i=1}^{m} v_{i} X_{i j} \leq 0, \quad j=1, \ldots . ., n$,

$\sum_{r=1}^{s} u_{r} Y_{r j}-\sum_{p=1}^{q} w_{p} Z_{p j} \leq 0, \quad j=1, \ldots ., n$,

$u_{r}, v_{i}, w_{p} \geq \varepsilon, \quad r=1, \cdots, s ; i=1, \cdots, m ; \quad p=1, \cdots, q$.

The dual of model (2) can be written as follows,

$E_{k}=\min a-\left(\sum_{i=1}^{m} s_{l}^{n}+\sum_{p=1}^{q} s_{p}^{w}+\sum_{w=1}^{s} s_{i}^{n}\right)$

subject to

$a x_{a}-\sum_{l=1}^{s} a_{j} X_{q}-\sum_{p=1}^{s} \beta_{t} x_{y}-s=0, \quad i=1, \ldots ., m$, 
$\sum_{j=1}^{n} \beta_{l} Z_{p l}-\sum_{j=1}^{a} \gamma_{l} Z_{p l}-s_{p}^{w}=0, \quad p=1, \ldots ., q$,

$\sum_{j=1}^{m} \alpha_{l} Y_{r j}+\sum_{j=1}^{s} \gamma_{l} Y_{r j}-s_{p}^{w}=Y_{r k}, \quad r=1, \ldots ., s$,

$\alpha_{j}, \beta_{l}, s_{l}^{w}, s_{p}^{w}, s_{r}^{w} \geq 0, \quad j=1, \ldots ., n ; r=1, \ldots ., s ; i=1, \ldots ., m ; \quad p=1, \ldots ., q$.

DEA model (2) and (3) can be implemented to measure the efficiency of various units. However, we require to be cautious on using the models for two reasons. First, the model is formulated for constant return to scale and second, the relative importance for the output of the first stage is the same as the input of the second stage. There are alternative procedure, which could be implemented whenever the return to scale would not be constant. Interested reader could see Kao and Hwang (1994) for more details.

\section{Case study}

In this section, we present the implementation of DEA methods for an application of insurance firms in Iran. The proposed study of this paper uses DEA model (2) and (3) to measure the relative efficiencies of the insurance firms. The proposed study of this paper performs DEA method in two stages where the first stage considers five inputs and three outputs while the second stage considers the outputs of the first stage as the inputs of the second stage and uses three different outputs for this stage. Fig. 2 one shows details of our proposed model.

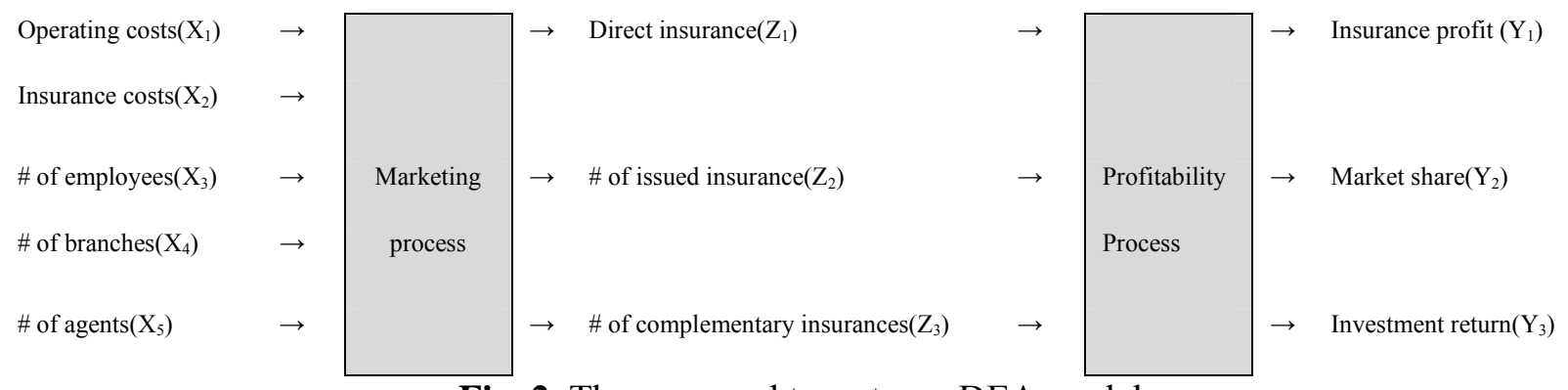

Fig. 2. The proposed two stages DEA model

Operating cost $\left(\mathrm{X}_{1}\right)$ is the first input, which includes employee wages and other operating expenditures. Insurance cost $\left(\mathrm{X}_{2}\right)$ is the second input of the first stage, which is associated with the cost of insurance marketing, the expenses paid to different agents and consultants. The number of employees who work for any insurance unit $\left(\mathrm{X}_{3}\right)$ is the third inputs of the first stage. The other input is the number of branches and central offices $\left(\mathrm{X}_{4}\right)$ and finally, the number of agents who are responsible to sell insurance $\left(\mathrm{X}_{5}\right)$ is the last input of the first stage. There are three outputs associated with first stage of the proposed model, which are also the inputs of the second stage. Direct insurance $\left(Z_{1}\right)$, which is the fees received directly from the customers is the first output, total number of insurance certificates $\left(Z_{2}\right)$ and Complementary insurance $\left(Z_{3}\right)$ is the second output, which are received from companies. As we can see from Fig. 1, the outputs of the first stage are considered as the inputs of the second stage. For the outputs of the second stage, we consider the net income from sales of insurances $\left(\mathrm{Y}_{1}\right)$, short term and long term investment returns $\left(\mathrm{Y}_{2}\right)$ and market share $\left(\mathrm{Y}_{3}\right)$. The study measure the relative efficiencies over the period of 2006-2010. We first calculate the efficiencies of these insurance firms in two stages independently and then multiply these numbers together to calculate the overall efficiencies. We also use the proposed model presented in Eq. (3) to measure the relative efficiencies. Table 1 demonstrates the relative efficiencies of these units over the 
period 2006-2008. Table 2 also shows the relative efficiencies of 20 insurance units over the period 2009-2010.

\section{Table 1}

The results of the relative efficiencies of 18 insurance firms over the period 2006-2008

\begin{tabular}{lccccccccc}
\hline & & 2006 & & & 2007 & & \multicolumn{2}{c}{2008} \\
\hline Insurance & $\mathrm{E}_{1}$ & $\mathrm{E}_{2}$ & $\mathrm{E}_{\mathrm{k}}$ & $\mathrm{E}_{1}$ & $\mathrm{E}_{2}$ & $\mathrm{E}_{\mathrm{k}}$ & $\mathrm{E}_{1}$ & $\mathrm{E}_{2}$ & $\mathrm{E}_{\mathrm{k}}$ \\
\hline 1 & 1 & 1 & 1 & 0.672 & 0.310 & 0.672 & 0.677 & 0.179 & 0.677 \\
2 & 0.234 & 0.149 & 0.349 & 1 & 1 & 1 & 1 & 0.137 & 1 \\
3 & 1 & 0.316 & 0.316 & 0.556 & 0.516 & 0.556 & 1 & 1 & 1 \\
4 & 0.347 & 1 & 0.347 & 0.338 & 1 & 0.338 & 1 & 1 & 0.316 \\
5 & 0.556 & 0.002 & 0.001 & 0.313 & 0.223 & 0.313 & 0.234 & 0.234 \\
6 & 0.338 & 0.039 & 0.013 & 0.347 & 0.236 & 0.347 & 0.358 & 0.483 & 0.358 \\
7 & 0.391 & 0.087 & 0.034 & 0.304 & 0.406 & 0.304 & 0.022 & 0.228 & 0.022 \\
8 & 0.482 & 0.348 & 0.168 & 0.483 & 0.215 & 0.483 & 0.135 & 0.360 & 0.135 \\
9 & 0.174 & 0.089 & 0.015 & 0.316 & 0.179 & 0.316 & 0.189 & 0.002 & 0.189 \\
10 & 0.330 & 0.022 & 0.007 & 0.228 & 0.303 & 0.228 & 0.022 & 0.328 & 0.022 \\
11 & 0.673 & 0.533 & 0.359 & 0.358 & 0.495 & 0.358 & 0.317 & 0.087 & 0.317 \\
12 & 0.447 & 0.081 & 0.036 & 0.022 & 0.364 & 0.022 & 0.221 & 0.255 & 0.221 \\
13 & 0.516 & 0.174 & 0.090 & 0.170 & 0.281 & 0.170 & 0.180 & 0.039 & 0.180 \\
14 & 0.661 & 0.074 & 0.049 & 0.647 & 0.221 & 0.647 & 0.179 & 0.251 & 0.179 \\
15 & 0.463 & 0.211 & 0.098 & 0.158 & 0.159 & 0.158 & 0.137 & 0.228 & 0.137 \\
16 & 0.538 & 0.179 & 0.096 & 0.315 & 0.009 & 0.315 & 0.316 & 0.333 & 0.316 \\
17 & 0.655 & 0.419 & 0.274 & 0.251 & 0.581 & 0.251 & 0.228 & 0.419 & 0.228 \\
18 & 0.492 & 0.022 & 0.011 & 0.228 & 0.112 & 0.228 & 0.002 & 0.022 & 0.002 \\
\hline Average & & & 0.181 & & & 0.373 & & & 0.345 \\
\hline
\end{tabular}

Table 2

The results of relative efficiencies of 20 insurance firms for the fiscal year of 2009 and 2010

\begin{tabular}{|c|c|c|c|c|c|c|}
\hline & \multicolumn{3}{|c|}{2009} & \multicolumn{3}{|c|}{2010} \\
\hline Insurance & $E_{1}$ & $E_{2}$ & $E_{k}$ & $E_{1}$ & $E_{2}$ & $E_{k}$ \\
\hline 1 & 0.310 & 0.552 & 0.171 & 0.875 & 0.251 & 0.220 \\
\hline 2 & 0.288 & 1 & 0.288 & 0.582 & 1 & 0.582 \\
\hline 3 & 1 & 1 & 1 & 1 & 1 & 1 \\
\hline 4 & 1 & 0.546 & 0.546 & 1 & 0.470 & 0.470 \\
\hline 5 & 0.588 & 0.174 & 0.102 & 0.515 & 1 & 0.515 \\
\hline 6 & 0.166 & 0.347 & 0.058 & 0.573 & 0.118 & 0.068 \\
\hline 7 & 0.236 & 0.556 & 0.131 & 0.591 & 0.129 & 0.076 \\
\hline 8 & 0.406 & 0.338 & 0.137 & 0.884 & 0.449 & 0.397 \\
\hline 9 & 0.495 & 0.377 & 0.187 & 0.524 & 0.233 & 0.122 \\
\hline 10 & 0.364 & 0.292 & 0.106 & 0.544 & 0.269 & 0.146 \\
\hline 11 & 0.073 & 0.313 & 0.023 & 0.578 & 0.117 & 0.068 \\
\hline 12 & 0.584 & 0.234 & 0.137 & 0.677 & 0.260 & 0.176 \\
\hline 13 & 0.475 & 0.672 & 0.319 & 0.524 & 0.390 & 0.204 \\
\hline 14 & 0.493 & 0.391 & 0.193 & 0.657 & 0.117 & 0.076 \\
\hline 15 & 0.457 & 0.447 & 0.204 & 0.631 & 0.251 & 0.158 \\
\hline 16 & 0.539 & 0.673 & 0.363 & 0.512 & 1 & 0.512 \\
\hline 17 & 0.747 & 0.482 & 0.360 & 0.769 & 0.556 & 0.428 \\
\hline 18 & 0.303 & 0.516 & 0.156 & 0.641 & 0.472 & 0.303 \\
\hline 19 & 0.281 & 0.492 & 0.138 & 0.012 & 0.761 & 0.438 \\
\hline 20 & 0.221 & 0.584 & 0.129 & 0.312 & 0.118 & 0.037 \\
\hline Average & & & 0.238 & & & 0.289 \\
\hline
\end{tabular}

As we can observe from the results of Table 1 and Table 2, the average efficiencies of insurance firms in all years were relatively low, which means a limited number units dominated the market compared with other insurance firms. Fig. 2 shows details of efficiencies and our judgment can be follows more precisely. 


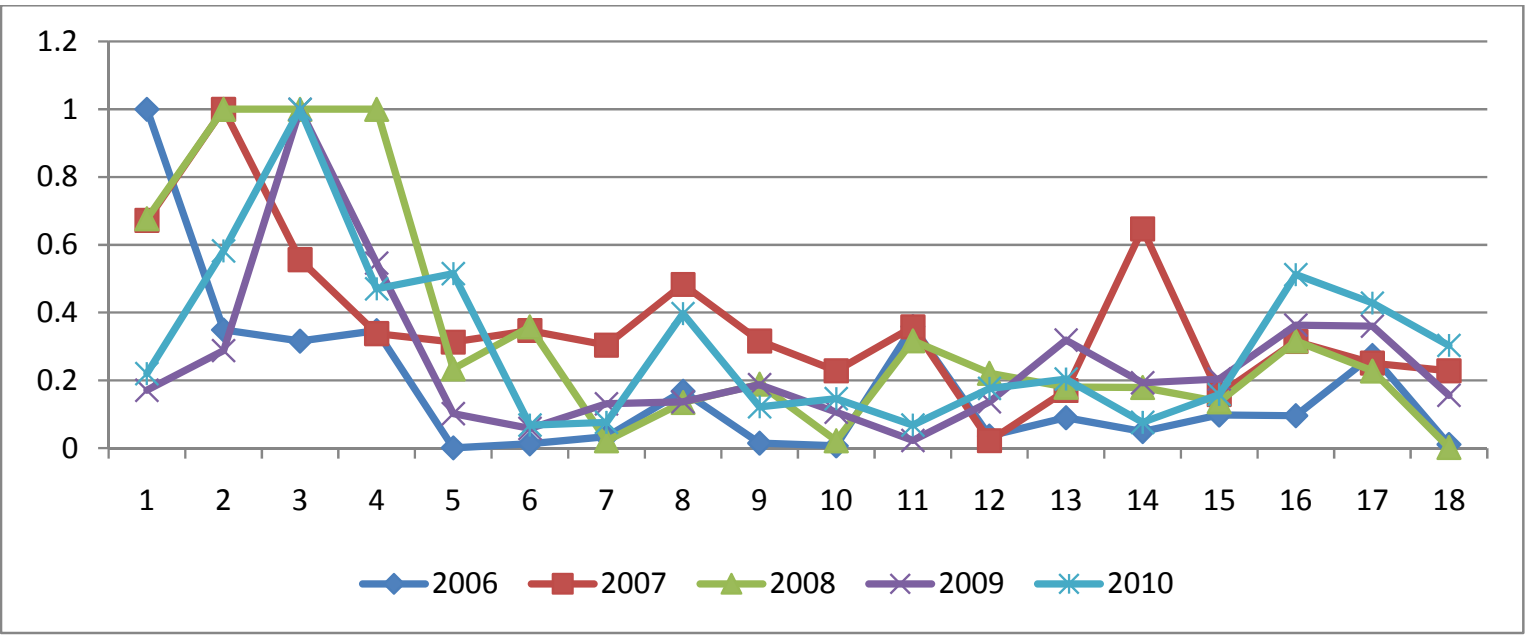

Fig. 2. The relative efficiencies of 18 units over the period 2006-2010

\section{Conclusion}

In this paper, we have presented an empirical investigation to measure the relative efficiencies of insurance firms in Iran. The proposed model of this paper has implemented two-stage DEA technique to measure the relative efficiencies of these units. The results of our survey have indicated that while there were 4 efficient insurance firms most other insurances were noticeably inefficient. This means market was monopolized mostly by a limited number of insurance firms and competition was not fare enough to let other firms participate in economy, more efficiently.

\section{References}

Banker, R.D., Charnes, A. \& Cooper, W.W. (1984). Some models for estimating technical and scale inefficiencies in data envelopment analysis. Management science, 30(9), 61-92.

Barros, C.P., Nektarios, M., \& Assaf, A. (2010). Efficiency in the Greek insurance industry. European Journal of Operational Research, 205(2), 431-436

Charnes A, Cooper, W. W., \& Rhodes, E. (1978). Measuring the efficiency of decision making units. European Journal of the Operational Research, 2, 429-44.

Charnes A, Cooper W. W., Lewin, A., \& Seiford, L. M. (1994). Data envelopment analysis: theory, methodology and applications. Massachusetts: Kluwer Academic Publishers.

Cooper, W.W., Seiford, L. M., \& Tone, K. (2000). Data envelopment analysis. Kluwer Academic Publication, Boston, Dordrecht, London.

Cummins, J.D., \& Xie, X. (2008). Mergers and acquisitions in the US property-liability insurance industry: Productivity and efficiency effects. Journal of Banking \& Finance, 32(1), 30-55

Cummins, J.D., Weiss, M.A., Xie, X., \& Zi, H. (2010). Economies of scope in financial services: A DEA efficiency analysis of the US insurance industry. Journal of Banking \& Finance, 34(7), 1525-1539.

Kao, C., \& Hwang, S-N. (2008). Efficiency decomposition in two-stage data envelopment analysis: an application to non-life insurance companies in Taiwan. European Journal of Operational Research, 185 (1), 418-429.

Yang, Z. (2006). A two-stage DEA model to evaluate the overall performance of Canadian life and health insurance companies. Mathematical and Computer Modelling, 43(7-8), 910-919.

Yao, S., Han, Z., \& Feng, G. (2007). On technical efficiency of China's insurance industry after WTO accession. China Economic Review, 18(1), 66-86. 